\title{
Knowledge, Attitude, and Practices towards COVID-19 during the Rapid Rise Period: A Cross-Sectional Survey among Public University Students of Bangladesh
}

\author{
Md Mostafizur Rahman ${ }^{1 *}$, Jannate Mehjabin Jhinuk ${ }^{1}$, Nadia Habib Nabila ${ }^{1}$, \\ Mir Taj Mira Yeasmin ${ }^{1}$, Ifta Alam Shobuj ${ }^{1}$, Tammim Hossain Sayma ${ }^{1}$, \\ Fariha Faruk ${ }^{1}$, Shakhawat Hossain Shah ${ }^{1}$ \\ ${ }^{l}$ Department of Disaster and Human Security Management, Faculty of Arts and Social Sciences, Bangladesh University of \\ Professionals, Mirpur Cantonment, Dhaka-1216, Bangladesh.
}

Received 05 February 2021; Revised 18 March 2021; Accepted 02 April 2021; Published 01 June 2021

\begin{abstract}
Bangladesh has experienced long term COVID-19 impact in the education sector where university students have suffered a lot. This cross-sectional study intended to evaluate the health behavior of public university students towards the COVID-19. The convenience sampling technique was employed during the rapid COVID-19 period. A total of 952 public university students participated in the KAP survey. Statistical analyses were performed depending on the data type. Study population demonstrated exemplary COVID-19 knowledge along with positive attitudes and preventive practices towards the COVID-19. Gender, university year, and major were determined as associating factors with their overall KAP. Female students reported better knowledge and practice regarding COVID-19 than their counterpart male students. Students living in the capital Dhaka city did not show positive attitudes towards COVID-19 compared to the students living outside the city. Students who were without their families demonstrated better attitudes compared to the students with their families. Broadcast media, print media, the internet, university, and social media were identified as sources of COVID-19 precautionary measures information for these students. Students showed better knowledge and attitude levels when used print media and university respectively compared to the students who used surrounding people as a source of information. This study enhances our understanding of the health behavior of public university students of Bangladesh. It has also determined the associating factors with their KAP level. The outcome of this study can assist the government, organizations, and the university to prepare for a comprehensive pandemic control effort.
\end{abstract}

Keywords: COVID-19; Developing Settlement; KAP Survey; Health Behavior; Bangladesh; University Students.

\section{Introduction}

COVID-19 was first reported in Wuhan, China in December 2019 [1-5]. It was then rapidly expanded to other countries, and in March 2020 the World Health Organization (WHO) announced this communicable disease as pandemic [3-5]. The international community has been struggling to cope up with the pandemic. The term "Coronophobia" has been shifted from the epicenter of China to Europe, United States, Brazil, and the South Asian region [6]. More than 200 countries have already been affected [7]. The frontline health sector has been paralyzed in many countries due to the pandemic $[4,8,9]$. Along with the direct health impact, the effect of this pandemic has

* Corresponding author: amimostafiz@gmail.com

do) http://dx.doi.org/10.28991/SciMedJ-2021-0302-4

$>$ This is an open access article under the CC-BY license (https://creativecommons.org/licenses/by/4.0/).

(C) Authors retain all copyrights. 
already been expanded to the socio-economic sector, education sector, human behavior, mental health, governance, and technology [8, 10, 11]. Developing countries have experienced both the direct and indirect COVID-19 overwhelming impact, and it has become an urgent issue to embrace effective actions $[2,12,13]$.

Bangladesh has always been on the top list of disaster-prone countries due to the frequent natural hazards [14-17]. This developing country has also a long history of infectious diseases outbreak [16, 18, 19]. The COVID-19 has triggered overwhelming negative impacts across the country. It has become the hardest-hit developing country during this pandemic $[10,11,20]$. The capital Dhaka city became the epicenter for COVID-19 spreading across the country. It has also recorded the highest COVID-19 cases in the country (COVID-19 General Information) [21]. The nearest neighboring country India recorded the 2nd highest COVID-19 cases after the United States [6]. Like many countries, Bangladesh had to declare the lockdown to control the outbreak. However, the authority has faced several challenges in the case of maintaining social distances, testing facilities, following preventive practices such as washing hands, ensuring face masks among the community [22, 23]. The rapid rate of COVID-19 cases was observed after the lifting of the lockdown period (COVID-19 General Information) [21]. People were observed with negative attitudes and practices towards the precautionary measures against the COVID-19. It has become an urgent issue to understand the health behavior towards the pandemic.

COVID-19 has triggered a new experience for countries across the world. It has been highly suggested to strictly follow authentic knowledge, positive attitudes, and preventive practices (KAP) to fight effectively against the pandemic. These positive health behaviors are required for effective COVID-19 response [5]. Students must have these behaviors to disseminate with other community people [24]. KAP survey has been widely used in many studies to evaluate the students' health behavior [2, 5, 25-29]. This study intended to examine the university students' health behavior towards the COVID-19. Students have become one of the worst affected groups due to the COVID-19 pandemic [10, 28, 30, 31]. They have experienced not only the direct COVID-19 impact on their health, but this young group of the society has also been struggling with the unprecedented academic consequences due to the pandemic. University students in Bangladesh were concerned about their mental health and study during the pandemic period $[10,31]$. Among them, public university students were affected most due to the lack of online academic facilities, poor network facilities, and poor financial conditions. Besides the negative impact, university students can also act as the central hub to disseminate positive health behavior towards their family members and community. Our study also investigated the association of students' socio-demographic and academic information with their health behavior towards the pandemic. The outcome of this study can provide substantial information regarding the COVID-19 pandemic among university students which can assist the government, non-governmental organizations, university authorities to prepare the comprehensive pandemic preparedness and response, the fundamental concern for many countries now.

\section{Methods}

\subsection{Research Design and Ethical Issue}

This cross-sectional study was designed to conduct during the rapid increase of COVID-19 period after lifting the lockdown period in Bangladesh (COVID-19 General Information) [21]. All educational institutions were closed except some online activities. Students from a government-funded public university in Dhaka city, Bangladesh University Professionals (BUP), participated in a self-reported rapid online KAP survey. This research was part of an approved research project from BUP. It has maintained all ethical issues. It has also been granted as part of approved research by the BUP Institutional Review Board (Research Ethics Committee). The cover page with informed consent described the purpose and confidentiality of the research. Participants have assured the confidentiality of their responses. No incentive was given. Participants had the complete right to leave the questionnaire at any time.

\subsection{Survey Instruments}

A draft questionnaire was prepared following the previous studies [28, 29]. A pilot survey among some university students was conducted. Expert's opinion and cultural appropriateness were also considered to validate and then prepared the final questionnaire. The reliability and internal consistency of the Likckert scale part in KAP section questionnaire were calculated as accepted Cronbach's alpha value $>0.60$ (Ursachi et al., 2015) [32]. The questionnaire was in English considering the English as medium of instruction in the university. It had three parts: sociodemographic, academic information, and the KAP section. The knowledge section had 14 close-ended items regarding the COVID-19 such as COVID-19 is pandemic or not, if they knew it before it entered the country, primary symptoms of this disease, early supporting treatment can help to recover, old people with chronic illness normally develop the severe cases, asymptomatic cases, infection more than once, spreading behavior, health behavioral knowledge to prevent the infection and emergency contact number for the health assistance in Bangladesh. All the items had binary responses (Yes/No) consisted of a 0-1 score range ( 1 for correct answer and 0 is for wrong answer). The attitude and practice section had 6 and 11 close-ended items respectively with 5-points Lickert scale (Strongly agree, Agree, Neutral, Disagree, and Strongly Disagree) as responses. Attitude section consisted of different agreements towards 
COVID-19 such as if the students are confident against COVID-19, development of COVID-19 vaccine, controlling of COVID-19, country's battle against COVID-19, and communication with the university and relevant organizations regarding COVID-19. Students rated on different preventive practices towards COVID-19 such as regular washing hands, maintaining distances, avoiding crowd, using mask when go outside, avoid touching face, covering mouth and nose during cough or sneeze, maintaining self-isolation even for minor symptoms, washing clothes after return home, cleaning the vegetables and fruits before eating and the following information from the trusted sources. Cut-off scores were calculated to categorize the score (high, moderate, and low) based on the quartile values in the KAP score. Details of this method can be found somewhere in previous studies [27-29].

\subsection{Sampling Design and Data Collection}

This study employed convenience sampling technique. A group of recruited and trained to distribute the online questionnaire. Different online media such as Google Classroom, Facebook, WhatsApp, Email services were used for this purpose. This study considered only the perception assessment study. The required sample size following Morgan's Table was 384 (95\% CI with a 5\% margin of error). We have received enormous responses. Approximately 1065 students were approached where 956 participated in the survey. Thus, the response rate was $89.76 \%$. A total of 952 responses were considered in the final analysis after the exclusion of 4 incomplete responses.

\subsection{Data Analysis}

All statistical analyses were conducted by using RStudio (version 1.2.5042; Boston, MA, USA) (RStudio | Open Source \& Professional Software for Data Science Teams) [33]. Descriptive statistics such as frequency, percentages, median and interquartile range were calculated where appropriate. Normality tests (Shapiro-Wilk and KolmogorovSmirnov tests) were performed. Since data were not normally distributed, non-parametric tests, such as Kruskal-Wallis or Mann-Whitney U tests were carried out to address the association between socio-demographic and academic information, and the KAP domain score. Chi-square tests were also performed to determine the association between KAP domain level (high, moderate, and low) and students' socio-demographic and academic information. Post hoc analyses were performed through Dunn's test. Bonferroni correction was applied for the p-value adjustment. Spearman's rank correlation test was carried out to determine the correlation in the KAP section. The linear regression model analysis and ANOVA were also performed to determine the knowledge and attitude as predictors of practices. All statistical analyses were conducted at $0.05 \alpha$ level.

\section{Results}

\subsection{Socio-demographic and Academic Information}

Table 1 presents the descriptive statistics of the participants where majority students were in 21-25 age range $(n=614,64.50 \%)$ following $15-20$ age range $(n=326,34.24 \%)$ students. Male $(n=472,49.58 \%)$ and female $(n=480$, $50.42 \%$ ) ratio was good among the participants. The majority of the participant students were living in the capital Dhaka city $(n=562,59.03 \%)$ where most of them were with their family $(n=886,93.06 \%)$. The majority of the participated university students were in the first year $(n=448,47.06 \%)$ followed by the second year $(n=292,30.67 \%)$. In the case of a major, many students were from Business Studies $(n=411,43.17 \%)$ and Arts and Social Sciences $(\mathrm{n}=353,37.08 \%)$. Majority of the study population received COVID-19 preventive information from Broadcast media (TV, radio) $(n=317,33.30 \%)$ followed by social media $(n=291,30.57 \%)$ and internet $(n=235,24.68 \%)$.

Table 1. Socio-demographic and academic features among the university students

\begin{tabular}{lcc}
\hline Features & Frequency & Percentage \\
\hline 1. Age & & \\
$15-20$ & 326 & 34.24 \\
$21-25$ & 614 & 64.50 \\
$26-30$ & 12 & 1.26 \\
2. Gender & & \\
$\quad$ Male & 472 & 49.58 \\
$\quad$ Female & 480 & 50.42 \\
3. Current Location & & \\
$\quad$ Dhaka & 562 & 59.03 \\
$\quad$ Outside Dhaka & 390 & 40.97 \\
4. Current Accommodation & & \\
With Family & & \\
Without Family & 886 & 93.07 \\
\end{tabular}




\begin{tabular}{lcc} 
5. University Year & & \\
$\quad$ First year & 448 & 47.06 \\
Second year & 292 & 30.67 \\
Third year & 159 & 16.70 \\
$\quad$ Fourth year & 53 & 5.57 \\
6. Major & & \\
$\quad$ Arts and Social Sciences & 353 & 37.08 \\
Business Studies & 411 & 43.17 \\
Security and Strategic Studies & 96 & 10.08 \\
$\quad$ Science and Technology & 92 & 9.66 \\
7. Sources of COVID-19 Precautionary Measures Information & & \\
Broadcast Media (TV, Radio) & 317 & 33.30 \\
Internet & 235 & 24.68 \\
People (Community, Family Members) & 74 & 7.77 \\
$\quad$ Print Media & 15 & 1.58 \\
$\quad$ Social Media & 291 & 30.57 \\
$\quad$ University & 20 & 2.10 \\
\hline
\end{tabular}

\subsection{COVID-19 Preventive Knowledge}

Table 2 shows the frequency and percentage of COVID-19 preventive knowledge among the participant university students. They reported exemplary knowledge regarding COVID-19. All of these students were aware of COVID-19 as a pandemic. They knew about COVID-19 before it entered their country ( $\mathrm{n}=919,96.53 \%)$, they were aware of the primary symptoms (fever, fatigue, and dry cough) of COVID-19 ( $\mathrm{n}=945,99.26 \%)$, early treatment can help most patients to recover $(\mathrm{n}=931,97.79 \%)$. They also realized that the old people are the most vulnerable group to the COVID-19 infection $(\mathrm{n}=719,83.93 \%)$ where they $(\mathrm{n}=871,91.49 \%)$ were also aware of presymptomatic and asymptomatic COVID-19 cases. They also agreed that there was a chance of COVID-19 infection more than once $(\mathrm{n}=811,85.19 \%)$. These university students knew that the pandemic could spread through infected individual's respiratory droplets $(\mathrm{n}=926,97.27 \%)$. They also had preventive knowledge against COVID-19 infection such as wearing a general medical mask, avoid crowded places, and regularly wash hands ( $\mathrm{n}=916,96.22 \%)$. The majority of the participant students believed that they had COVID-19 information from the authentic sources $(\mathrm{n}=852,89.50 \%)$, they knew the emergency number (333) in case of any COVID-19 health assistance in Bangladesh ( $\mathrm{n}=811,85.19 \%$ ), they claimed some home cares that may help somehow to recover from COVID-19 infection ( $\mathrm{n}=824,86.55 \%)$. The majority of them also knew the concept and importance of quarantine, isolation, and lockdown ( $\mathrm{n}=942,98.95 \%)$.

Table 2. COVID-19 preventive knowledge among university students

\begin{tabular}{lcc}
\hline Statements & $\begin{array}{c}\text { Expected Responses } \\
(\boldsymbol{n}(\boldsymbol{\%}))\end{array}$ & $\begin{array}{c}\text { Unexpected Responses } \\
(\boldsymbol{n}(\boldsymbol{\%}))\end{array}$ \\
\hline COVID-19 is Pandemic & $952(100.00)$ & $0(0.00)$ \\
I knew about COVID-19 before it entered Bangladesh & $919(96.53)$ & $33(3.47)$ \\
I know about the primary symptoms (Fever, Fatigue and Dry cough) of COVID-19 & $945(99.26)$ & $07(0.74)$ \\
Early symptomatic and supportive treatment can help most patients to recover & $931(97.79)$ & $21(2.21)$ \\
Old people with chronic illness with COVID-19 normally develop severe cases & $799(83.93)$ & $153(16.07)$ \\
Person with Coronavirus but no symptom can infect others & $871(91.49)$ & $81(8.51)$ \\
People can be infected by COVID-19 more than once & $811(85.19)$ & $141(14.81)$ \\
COVID-19 can spread via respiratory droplets of infected individuals & $926(97.27)$ & $26(2.73)$ \\
Wear general medical mask, avoid crowded places and Regular wash hand can & $916(96.22)$ & $36(3.78)$ \\
prevent from COVID-19 infection & $936(98.32)$ & $16(1.68)$ \\
Immediate Isolation and treatment of infected people can reduce the spread & $852(89.50)$ & $100(10.50)$ \\
I keep in touch with updated information of COVID-19 from authentic source & $824(86.55)$ & $128(13.45)$ \\
I know some home treatments which can help to recover from COVID-19 & $811(85.19)$ & $141(14.81)$ \\
I know the emergency number for COVID-19 (333) health assistance in Bangladesh & $942(98.95)$ & $10(1.05)$ \\
I know the concept of being quarantine, isolation and lockdown &
\end{tabular}




\subsection{Attitude Towards COVID-19 Pandemic}

Table 3 presents the attitude towards the COVID-19 among the study population. Most of them agreed on positive attitudes towards the COVID-19. The majority of them were confident in their protection from COVID-19 infection $(n=437,45.90 \%)$. Many of them were agreed that the COVID-19 vaccine would be developed soon $(n=450,47.27 \%)$ where the national and international community would win in the long-term battle against the pandemic. The majority of these students were agreed that they had enough communication with their university $(n=439,46.11 \%)$ and other relevant organizations $(n=336,35.29 \%)$ for COVID-19 emergency support.

Table 3. Attitude towards COVID-19 pandemic

\begin{tabular}{|c|c|c|c|c|c|}
\hline Statements & $\begin{array}{c}* \text { SA } \\
(n(\%)) \\
\end{array}$ & $\begin{array}{c}* \mathbf{A} \\
(n(\%)) \\
\end{array}$ & $\begin{array}{c}* \mathbf{N} \\
(n(\%)) \\
\end{array}$ & $\begin{array}{c}\text { *DA } \\
(n(\%)) \\
\end{array}$ & $\begin{array}{c}\text { *SDA } \\
(n(\%)) \\
\end{array}$ \\
\hline I can protect myself from COVID-19 infection & $204(21.43)$ & $437(45.90)$ & $251(26.37)$ & $46(4.83)$ & $14(1.47)$ \\
\hline COVID-19 vaccine will be developed soon & $164(17.23)$ & $450(47.27)$ & $280(29.41)$ & $51(5.36)$ & $07(0.74)$ \\
\hline COVID-19 will finally be successfully controlled & $130(13.66)$ & $363(38.13)$ & $327(34.35)$ & $103(10.82)$ & $29(3.05)$ \\
\hline Bangladesh will win in the battle against COVID-19 & $88(9.24)$ & $302(31.72)$ & $325(34.14)$ & $154(16.18)$ & $83(8.72)$ \\
\hline $\begin{array}{l}\text { I have enough communication with my university for any } \\
\text { emergency COVID-19 support }\end{array}$ & $139(14.60)$ & $439(46.11)$ & $226(23.74)$ & $118(12.39)$ & $30(3.15)$ \\
\hline $\begin{array}{l}\text { I have enough communication with relevant organizations for any } \\
\text { emergency COVID-19 support }\end{array}$ & $103(10.82)$ & $336(35.29)$ & $291(30.57)$ & $189(19.85)$ & $33(3.47)$ \\
\hline
\end{tabular}

*SA= Strongly Agree, A=Agree, N=Neutral, DA=Disagree and SDA=Strongly Disagree.

\subsection{Practices towards COVID-19 Pandemic}

Table 4 presents the preventive practices followed by the university students. Many of them were strongly agreed in following good practices against COVID-19 such as regular hand washing with alcohol-based hand rub or soap and water $(n=474,49.79 \%)$, wear a mask when going outside $(n=577,60.61 \%)$, staying home in case of any COVID-19 symptoms $(n=407,42.75 \%)$, wash or change clothes after return from outside $(n=497,52.21 \%)$, wash vegetables and fruits before eating $(n=524,55.04 \%)$. Many participant students were also agreed that they maintained social distance (minimum 1-meter) from others $(n=436,45.80 \%)$, avoid crowded places $(n=398,41.81 \%)$, avoid touching eyes, nose, and mouth $(n=399,41.91 \%)$, covering mouth and nose with the bent elbow or tissue during cough or sneeze, communication with the local authority for medical support $(n=387,40.65 \%)$, following latest COVID-19 relevant information from the authentic sources $(n=455,47.79 \%)$.

Table 4. Preventive practices towards COVID-19

\begin{tabular}{|c|c|c|c|c|c|}
\hline Statements & $\begin{array}{c}* \text { SA } \\
(n(\%))\end{array}$ & $\begin{array}{c}* \mathbf{A} \\
(n(\%))\end{array}$ & $\begin{array}{c}* \mathbf{N} \\
(n(\%))\end{array}$ & $\begin{array}{c}* \text { DA } \\
(n(\%))\end{array}$ & $\begin{array}{c}* \text { SDA } \\
(n(\%))\end{array}$ \\
\hline $\begin{array}{l}\text { I regularly and thoroughly wash my hands with an } \\
\text { alcohol-based hand rub or wash them with soap and } \\
\text { water. }\end{array}$ & $474(49.79)$ & 403 (42.33) & $59(6.20)$ & $12(1.26)$ & $04(0.42)$ \\
\hline $\begin{array}{l}\text { I maintain minimum 1-meter ( } 3 \text { feet) distance from } \\
\text { others. }\end{array}$ & 272 (28.57) & $436(45.80)$ & $165(17.33)$ & $70(7.35)$ & $09(0.95)$ \\
\hline I always avoid Crowded Places. & $370(38.87)$ & $398(41.81)$ & $138(14.50)$ & $36(3.78)$ & $10(1.05)$ \\
\hline I always wear mask when go outside. & $577(60.61)$ & $297(31.20)$ & $57(5.99)$ & $19(2.00)$ & $02(0.21)$ \\
\hline I always avoid touching my eyes, nose and mouth. & $264(27.73)$ & $399(41.91)$ & $194(20.38)$ & $82(8.61)$ & $13(1.37)$ \\
\hline $\begin{array}{l}\text { I cover my mouth and nose with my bent elbow or } \\
\text { tissue when cough or sneeze and then dispose the tissue } \\
\text { and wash my hands immediately. }\end{array}$ & 388 (40.76) & 415 (43.59) & $110(11.55)$ & $32(3.36)$ & $07(0.74)$ \\
\hline $\begin{array}{l}\text { I stay home and self-isolate even with minor symptoms } \\
\text { such as cough, headache, mild fever, until recover. }\end{array}$ & $407(42.75)$ & $386(40.55)$ & $120(12.61)$ & $32(3.36)$ & $07(0.74)$ \\
\hline $\begin{array}{l}\text { I always Wash or Change Clothes after return from } \\
\text { outside. }\end{array}$ & $497(52.21)$ & $338(35.50)$ & $82(8.61)$ & $29(3.05)$ & $06(0.63)$ \\
\hline $\begin{array}{l}\text { I always Wash vegetables and fruits thoroughly with } \\
\text { clean water before eating. }\end{array}$ & $524(55.04)$ & 352 (36.97) & $55(5.78)$ & $19(2.00)$ & $02(0.21)$ \\
\hline $\begin{array}{l}\text { I call in advance local health authority and follow the } \\
\text { directions for medical care early particularly in } \\
\text { COVID-19 pandemic. }\end{array}$ & 197 (20.69) & $387(40.65)$ & $252(26.47)$ & 99 (10.40) & 17 (1.79) \\
\hline $\begin{array}{l}\text { I follow the latest information from trusted sources, } \\
\text { such as WHO or local and national health authorities. }\end{array}$ & $339(35.61)$ & $455(47.79)$ & $120(12.61)$ & $30(3.15)$ & $08(0.84)$ \\
\hline
\end{tabular}




\subsection{KAP Domain Level and Score}

Table 5 shows the significant associations of socio-demographic and academic information with their KAP level. The majority of the study population reported high knowledge levels $(42.12 \%)$ followed by moderate knowledge levels $(33.30 \%)$. In the case of high knowledge levels, significant associations were observed for gender (female $=$ $45.42 \%$ vs. male $=38.77 \%$ ). In the case of majors, post hoc analysis identified the significant associations between Science and Technology major students and moderate knowledge levels (48.91\%). Strong significant associations were observed between the sources of COVID-19 precautionary measures information and students' knowledge level. Students having information from print media reported significantly high knowledge level $(80.00 \%)$ compared to the students who used people $(24.32 \%)$ only as media. $51.05 \%$ of the participants reported moderate attitude levels followed by low attitude levels (32.14\%). Male students showed significantly high attitude levels (19.92\%) compared to the female students $(13.75 \%)$. Students who were in Dhaka city reported significantly low attitude levels $(35.94 \%)$ than the students outside of this city $(26.67 \%)$. Students who were without their families reported significantly high attitude levels $(31.82 \%)$ compared to the students living with their families $(15.69 \%)$. In the case of the university year, significantly good proportions of fourth-year students reported high attitude levels (33.96\%) than the first and second-year students $(13.84 \%$ and $13.70 \%)$.

Significant associations were observed regarding COVID-19 precautionary information and students' attitude level, significantly high attitude levels were observed who followed university $(45.00 \%)$ as a medium of the source. The majority of the participants followed moderate practice levels (54.73) and low practice levels (25.21\%). Significant associations were reported between the age group, gender, university year, major, and practice levels. Post hoc analysis identified the significant associations between age group and low practice levels. The 26-30 age group reported significantly low practice levels $(66.67 \%)$. Female students followed significantly high practice levels $(23.54 \%)$ compared to the male students $(16.53 \%)$. Fourth-year students reported significantly high practice levels $(32.08 \%)$ than the second-year students (15.75\%). Significant associations were determined between Science and Technology major students and low practice levels (40.22\%). 49.37\% of participants reported moderate total KAP level followed by low total KAP level (28.36\%). Significant associations were also found in the case of age group, gender, university year, and total KAP level. The 15-20 age group was significantly associated with low total KAP levels $(20.86 \%)$. In the case of gender, female students were significantly associated with high total KAP levels $(23.12 \%)$ where first-year students were significantly associated with moderate total KAP levels $(55.58 \%)$.

Table 6 summarizes the significant associations of socio-demographic and academic information with the score in the KAP domain. Female students reported significantly more COVID-19 knowledge scores than male students. Post hoc analysis identified that the students who had information from people (community, family members) reported significantly less knowledge score when compared with the students who received information from broadcast media ( $\mathrm{TV}$, radio), internet, print media, and social media. Dhaka city residents demonstrated significantly less attitude scores towards COVID-19 infection. In the case of living with family, significant associations were also observed when considered the attitude scores like the previous result (Table 5). Significant associations were observed between attitude scores and university year. Post hoc analysis identified the third-year and fourth-year students reported significantly high attitude scores compared to the junior students.

Significant associations were found between the attitude scores and the source of COVID-19 precautionary information. After post hoc analysis, it was identified that the students who received COVID-19 precautionary measures information from the internet only, reported significantly less attitude scores compared with the students who received information from broadcast media, print media, and their university. 15-20 age group students reported significantly more practice scores when compared with students of 21-25 age group (after post hoc analysis). Female students reported significantly more practice scores compared to their counterpart male students. Post hoc analysis showed that the first-year students reported significantly more practice scores when compared with second-year students. Students major in Science and Technology reported significantly less practice scores compared to the students from Arts and Social Sciences, and Business Studies. In the case of total KAP score, significant associations were observed when compared the students' gender, university year, and major. Female students reported significantly more total KAP scores compared to male students. First-year students reported significantly more total KAP scores when compared with the total KAP score of second-year students (after post hoc analysis). Post hoc analysis was also conducted in case of major. Students major in Science and Technology reported significantly less total KAP scores when compared to the students from Arts and Social Sciences and Business Studies. 
Table 5. Significant associations of socio-demographic and academic features with KAP domain level

\begin{tabular}{|c|c|c|c|}
\hline \multirow{2}{*}{ Features } & \multicolumn{3}{|c|}{ Level $(n(\%))$} \\
\hline & High & Moderate & Low \\
\hline Knowledge Level & $401(42.12)$ & $317(33.30)$ & 234 (24.58) \\
\hline \multicolumn{4}{|l|}{ 1. Gender* } \\
\hline Male & $183(38.77)$ & $154(32.63)$ & $135(28.60)$ \\
\hline Female & $218(45.42)$ & $163(33.96)$ & $99(20.62)$ \\
\hline \multicolumn{4}{|l|}{ 2. Major** } \\
\hline Arts and Social Sciences & $147(41.64)$ & $121(34.28)$ & $85(24.08)$ \\
\hline Business Studies & $177(43.07)$ & $117(28.47)$ & $177(28.47)$ \\
\hline Security and Strategic Studies & $45(46.88)$ & $34(35.42)$ & $45(17.71)$ \\
\hline Science and Technology & $32(34.78)$ & $45(48.91)$ & $32(16.30)$ \\
\hline \multicolumn{4}{|l|}{$\begin{array}{l}\text { 3. Sources of COVID-19 Precautionary } \\
\text { Measures Information } * * *\end{array}$} \\
\hline Broadcast Media (TV, Radio) & $129(40.69)$ & $124(39.12)$ & $64(20.19)$ \\
\hline Internet & $110(46.81)$ & $67(28.51)$ & $58(24.68)$ \\
\hline People (Community, Family Members) & $18(24.32)$ & $27(36.49)$ & $29(39.19)$ \\
\hline Print Media & $12(80.00)$ & $02(13.33)$ & $01(6.67)$ \\
\hline Social Media & $125(42.96)$ & $91(31.27)$ & $75(25.77)$ \\
\hline University & $07(35.00)$ & $06(30.00)$ & $07(35.00)$ \\
\hline Attitude Level & $160(16.81)$ & $486(51.05)$ & $306(32.14)$ \\
\hline \multicolumn{4}{|l|}{ 1. Gender* } \\
\hline Male & $94(19.92)$ & $231(48.94)$ & $147(31.14)$ \\
\hline Female & $66(13.75)$ & $255(53.12)$ & $159(33.12)$ \\
\hline \multicolumn{4}{|l|}{ 2. Current Location $* *$} \\
\hline Dhaka & $92(16.37)$ & $268(47.69)$ & $202(35.94)$ \\
\hline Outside Dhaka & $68(17.44)$ & $218(55.90)$ & $104(26.67)$ \\
\hline \multicolumn{4}{|l|}{ 3. Current Accommodation*** } \\
\hline With Family & $139(15.69)$ & $455(51.35)$ & $292(32.96)$ \\
\hline Without Family & $21(31.82)$ & $31(46.97)$ & $14(21.21)$ \\
\hline \multicolumn{4}{|l|}{ 4. University Year**** } \\
\hline First year & $62(13.84)$ & $255(56.92)$ & $131(29.24)$ \\
\hline Second year & $40(13.70)$ & $134(45.89)$ & $118(40.41)$ \\
\hline Third year & $40(25.16)$ & $76(47.80)$ & $43(27.04)$ \\
\hline Fourth year & $18(33.96)$ & $21(39.62)$ & $14(26.42)$ \\
\hline \multicolumn{4}{|l|}{$\begin{array}{l}\text { 5. Sources of COVID-19 Precautionary } \\
\text { Measures Information } * * *\end{array}$} \\
\hline Broadcast Media (TV, Radio) & $58(18.30)$ & $172(54.26)$ & $87(27.44)$ \\
\hline Internet & $24(10.21)$ & $121(51.49)$ & $90(38.30)$ \\
\hline People (Community, Family Members) & $12(16.22)$ & $40(54.05)$ & $22(29.73)$ \\
\hline Print Media & $04(26.67)$ & $11(73.33)$ & $0(0.00)$ \\
\hline Social Media & $53(18.21)$ & $135(46.39)$ & $103(35.40)$ \\
\hline University & $09(45.00)$ & $07(35.00)$ & $04(20.00)$ \\
\hline Practice Level & $191(20.06)$ & $521(54.73)$ & $240(25.21)$ \\
\hline \multicolumn{4}{|l|}{ 1. Age A** $^{*}$} \\
\hline $15-20$ & $66(20.25)$ & $205(62.88)$ & $55(16.87)$ \\
\hline $21-25$ & $124(20.20)$ & $313(50.98)$ & $177(28.83)$ \\
\hline $26-30$ & $01(8.33)$ & $03(25.00)$ & $08(66.67)$ \\
\hline \multicolumn{4}{|l|}{ 2. Gender** } \\
\hline Male & $78(16.53)$ & $254(53.81)$ & $140(29.66)$ \\
\hline
\end{tabular}




\begin{tabular}{|c|c|c|c|}
\hline \multirow{2}{*}{ Features } & \multicolumn{3}{|c|}{ Level $(n(\%))$} \\
\hline & High & Moderate & Low \\
\hline Female & $113(23.54)$ & $267(55.62)$ & $100(20.83)$ \\
\hline \multicolumn{4}{|l|}{ 3. University Year $* * * *$} \\
\hline First year & $99(22.10)$ & $263(58.71)$ & $86(19.20)$ \\
\hline Second year & $46(15.75)$ & $163(55.82)$ & $83(28.42)$ \\
\hline Third year & $29(18.24)$ & $70(44.03)$ & $60(37.74)$ \\
\hline Fourth year & $17(32.08)$ & $25(47.17)$ & $11(20.75)$ \\
\hline \multicolumn{4}{|l|}{ 4. Major** } \\
\hline Arts and Social Sciences & $73(20.68)$ & $188(53.26)$ & $92(26.06)$ \\
\hline Business Studies & $90(21.90)$ & $234(56.93)$ & 87 (21.17) \\
\hline Security and Strategic Studies & $14(14.58)$ & $58(60.42)$ & $24(25.00)$ \\
\hline Science and Technology & $14(15.22)$ & $41(44.57)$ & $37(40.22)$ \\
\hline Total KAP Level & $212(22.27)$ & $470(49.37)$ & $270(28.36)$ \\
\hline \multicolumn{4}{|l|}{ 1. $\operatorname{Ag} e^{* * *}$} \\
\hline $15-20$ & $67(20.55)$ & $191(58.59)$ & $68(20.86)$ \\
\hline $21-25$ & $143(23.29)$ & $276(44.95)$ & $195(31.76)$ \\
\hline $26-30$ & $02(16.67)$ & $03(25.00)$ & $07(58.33)$ \\
\hline \multicolumn{4}{|l|}{ 2. Gender* } \\
\hline Male & $101(21.40)$ & $218(46.19)$ & $153(32.42)$ \\
\hline Female & $111(23.12)$ & $252(52.50)$ & $117(24.38)$ \\
\hline \multicolumn{4}{|l|}{ 3. University Year $* * * *$} \\
\hline First year & $98(21.88)$ & $249(55.58)$ & $101(22.54)$ \\
\hline Second year & $50(17.12)$ & $98(49.32)$ & $98(33.56)$ \\
\hline Third year & $46(28.93)$ & $56(35.85)$ & $56(35.22)$ \\
\hline Fourth year & $18(33.96)$ & $15(37.74)$ & $15(28.30)$ \\
\hline
\end{tabular}

${ }^{*} \mathrm{p}<0.05 ; * * \mathrm{p}<0.01 ; * * * \mathrm{p}<0.001$

Table 6. Significant associations of socio-demographic and academic features with KAP domain score

\begin{tabular}{|c|c|c|c|c|}
\hline Features & $\begin{array}{c}\text { Knowledge } \\
\text { (Median (IQR)) }\end{array}$ & $\begin{array}{c}\text { Attitude } \\
\text { (Median (IQR)) }\end{array}$ & $\begin{array}{c}\text { Practice } \\
\text { (Median (IQR)) }\end{array}$ & $\begin{array}{c}\text { Total KAP } \\
\text { (Median (IQR)) }\end{array}$ \\
\hline 1. Age & & & $* *$ & \\
\hline $15-20$ & & & $47(7.00)$ & \\
\hline $21-25$ & & & $46(9.00)$ & \\
\hline $26-30$ & & & $41.50(4.25)$ & \\
\hline 2. Gender & $*$ & & $* * *$ & $* *$ \\
\hline Male & $13(2.00)$ & & $45(8.00)$ & $79(11.00)$ \\
\hline Female & $13(1.00)$ & & $47(7.00)$ & $81(10.00)$ \\
\hline 3. Current Location & & $* *$ & & \\
\hline Dhaka & & $21(5.00)$ & & \\
\hline Outside Dhaka & & $21(5.00)$ & & \\
\hline 4. Current Accommodation & & $* * *$ & & \\
\hline With Family & & $21(4.00)$ & & \\
\hline Without Family & & $23(5.00)$ & & \\
\hline 5. University Year & & $* * *$ & $* *$ & $* *$ \\
\hline First year & & $21(4.00)$ & $47(8.00)$ & $81(10.00)$ \\
\hline Second year & & $20(5.00)$ & $45(8.00)$ & $79(11.00)$ \\
\hline Third year & & $23(5.50)$ & $46(10.5)$ & $80(14.00)$ \\
\hline Fourth year & & $22(7.00)$ & $47(10.00)$ & $81(14.00)$ \\
\hline
\end{tabular}




\begin{tabular}{|c|c|c|c|c|}
\hline Features & $\begin{array}{c}\text { Knowledge } \\
\text { (Median (IQR)) }\end{array}$ & $\begin{array}{c}\text { Attitude } \\
\text { (Median (IQR)) }\end{array}$ & $\begin{array}{c}\text { Practice } \\
\text { (Median (IQR)) }\end{array}$ & $\begin{array}{c}\text { Total KAP } \\
(\text { Median }(\text { IQR) })\end{array}$ \\
\hline 6. Major & & & $* * *$ & $*$ \\
\hline Arts and Social Sciences & & & $46(9.00)$ & $81(11.00)$ \\
\hline Business Studies & & & $47(8.00)$ & $80(12.00)$ \\
\hline $\begin{array}{l}\text { Security and Strategic } \\
\text { Studies }\end{array}$ & & & $45(7.50)$ & $80(8.25)$ \\
\hline Science and Technology & & & $44(8.00)$ & $79(11.25)$ \\
\hline $\begin{array}{l}\text { 7. Sources of COVID-19 } \\
\text { Precautionary Measures } \\
\text { Information }\end{array}$ & $* * *$ & $* * *$ & & \\
\hline $\begin{array}{l}\text { Broadcast Media (TV, } \\
\text { Radio) }\end{array}$ & $13(1.00)$ & $21(5.00)$ & & \\
\hline Internet & $13(1.00)$ & $20(5.00)$ & & \\
\hline $\begin{array}{l}\text { People (Community, } \\
\text { Family Members) }\end{array}$ & $13(1.00)$ & $21.5(5.00)$ & & \\
\hline Print Media & $14(0.00)$ & $24(2.50)$ & & \\
\hline Social Media & $13(2.00)$ & $21(5.50)$ & & \\
\hline University & $13(2.00)$ & $24(7.00)$ & & \\
\hline
\end{tabular}

${ }^{*} \mathrm{p}<0.05 ; * * \mathrm{p}<0.01 ; * * * \mathrm{p}<0.001$.

\subsection{Correlation in KAP Domain}

Table 7 showed strong correlations between knowledge and attitude, knowledge and practice, attitude and practice. Linear regression analysis also determined the knowledge and attitude as significant predictors $(\mathrm{p}<0.001)$ of practice. $\mathrm{R}^{2}=0.149$ was calculated for the overall model. ANOVA also identified the significance of the regression analysis $(\mathrm{p}<0.001)$.

Table 7. Correlation in KAP domain regarding COVID-19

\begin{tabular}{lccc}
\hline Association & r-value & p-value & Interpretation \\
\hline Knowledge and Attitude & 0.270 & $<0.001$ & Positive Correlation \\
Knowledge and Practice & 0.265 & $<0.001$ & Positive Correlation \\
Attitude and Practice & 0.312 & $<0.001$ & Positive Correlation \\
\hline $\mathrm{r}=$ correlation coefficient. & & &
\end{tabular}

\section{Discussion}

The education sector of Bangladesh has been affected to a great extent due to the COVID-19 pandemic [28]. The current study was conducted during the rapid rise of COVID-19 cases. The chances of infection might have increased at this period, which urged the effective COVID-19 response [5]. Due to the closure of the university campus, the majority of the students were living with their families across the country. This study revealed that broadcast media, social media, university, and the internet played substantial roles in the case of awareness build-up regarding the COVID-19 among public university students.

The present study revealed that the public university students had exemplary COVID-19 preventive knowledge. It contradicts the previous study Rahman et al. (2021) [28] conducted during the lockdown period among all university students of Bangladesh. It has shown that the knowledge level might improve over the period. These students also reported positive attitudes towards the pandemic which was also absent in the previous study [28]. However, attitude should be reflected in the implementation of knowledge through preventive practices. This study also revealed the good practices among the participated university students. Participants' knowledge about presymptomatic and asymptomatic COVID-19 cases, the chance of infection more than once, trust in the national and international authority, enough communication with the university and organizations in case of COVID-19 emergency, preventive practices such as wash hand with alcohol-based hand rub or soap, wearing masks, wash raw foods before eating, maintaining social distancing, avoid touching the faces, following latest information from the trusted sources have indicated the positive health behavior among these students towards the COVID-19.

This study demonstrated that the university students in the 15-20 age group followed more preventive practices towards the COVID-19. These students might have more access to the media accelerating their COVID-19 preventive behavior. The current study revealed that the female university students had better health behavior compared to their counterpart male students. It also supports the previous studies Covid-19 (2020) [34], Rahman et al., (2021) [28] and 
Walter \& McGregor (2020) [35]. Male can have more chances of infection due to several biological, behavioral, and cultural factors. It should be noteworthy that females are generally more concerned about safety and security than males in Bangladesh perspective. Even though these students normally live in Dhaka for their academic purpose, they had to move to their hometown during the pandemic. This study demonstrated that the university students who were living in Dhaka city during the survey reported poor health behavior towards COVID-19 compared to the Dhaka city outsiders. It has triggered the alarming message to the worst COVID-19 affected Dhaka city community. Dhaka city has already been affected by several urban hazards [36-39]. It has a high risk of earthquakes. Along with the high density of population and lack of awareness, this city's community has become one of the most vulnerable groups in the world [39-42].

University students who were without their families showed better health behavior than the students who were with their families. The possible explanation could be students living alone might realize the importance of self-protection against COVID-19. They reported positive attitudes towards the COVID-19. However, this result also gives an alarming message to the students' family members. Students who were with their family members must be concerned about COVID-19 infection to protect themselves and their family members. Fourth-year students were found with better attitude and practice levels compared to the new students. Bangladesh government should integrate comprehensive disaster management (including pandemic) academic activities in all levels of the educational curriculum. In the case of university-level education, this curriculum should be systematically applied based on the university year [43, 44]. This study also demonstrated the university students major in Science and Technology with poor health behavior compared to the students major in Arts and Social Sciences, and Business Studies. It also supports previous studies Rahman et al. (2021) [28] and Tan et al. (2017) [44], where the university students major in Arts and Social Sciences reported more COVID-19 related subjects in their curriculum and they also showed interest in relevant subjects. The current study revealed that the students connected more with the broadcast media, print media, social media, and university for COVID-19 precautionary measures information, reported better COVID-19 preventive behavior compared to the students who had information from their community and people only. Media has already played substantial role during COVID-19 pandemic [45-47].

University could help to build up the attitude level of the students. COVID-19 pandemic was completely new expereince for many countries, and it required new knowledge, attitude and practices for many cultures and societies. In case of Bangladesh society, social distancing was very uncommon, and people tend to be interacted with each other. Regular hand wash with alcohol-based hand rub, wearing mask, cover face when cough and sneeze have become completely new practices among the societies of Bangladesh. Awareness on COVID-19 pandemic has become urgent issue with authentic information. Media can contribute to reach these people with the authentic knowledge, it can also increase their confident level and confirm the required practices to prevent COVID-19 infection. Bangladesh government can consider some digital media (internet, social media and broadcast media) and mobile application to reach the university students. Authority should have the collaborative approach with the university and vice-versa. These students can then share their COVID-19 preventive information with their family members and thus the community people can have positive health behavior against the ongoing COVID-19 or any future outbreak.

This study also figured out the knowledge and attitude as predictors of practice for the study population. It disclosed that knowledge can direct to positive attitudes and then these positive attitudes can ensure effective preventive practices towards the pandemic. Our study through an online KAP survey may not reflect all university students of Bangladesh. However, this exploratory study can provide insight information about health behavior towards COVID-19 among the worst affected public university students of Bangladesh. It can also assist the government, organizations, community, and the university to prepare their students that they can have better health behavior towards the pandemic.

\section{Conclusion}

University students can contribute to preparing their community people since they have good access to digital media. The ongoing COVID-19 pandemic required positive health behavior such as authentic knowledge, positive attitude, and preventive practices to control the outbreak. University students can assist in this purpose. If they have authentic knowledge, positive attitudes, and regular precautionary practices, they cannot only protect themselves, they can also assist their family members and community people through sharing that knowledge, directing their attitudes, and implementing the required practices. In this way, the whole community and society can have better health behavior against the COVID-19. The present study disclosed the association of students' socio-demographic and academic information with their health behavior during the rapid rise of the COVID-19 period. The male students were found more vulnerable than their counterpart female students. Government, organizations, and the university need to focus on this group of students. Broadcast media and universities can play a substantial role along with the current popular social media. Authentic information should be disseminated through these media to reach university students. Besides, the mobile application can be an effective communication tool to track vulnerable university students and then intervene to strengthen their health behavior. Even though some countries have already started the 
vaccination campaign, it has been highly suggested to strictly follow preventive health behavior to reduce the further outbreak. A collaborative approach is required among the government, academician, university authority and the community to win the long-term battle against the long-term pandemic.

\section{Declarations}

\subsection{Author Contributions}

Conceptualization, M.R., J.J., N.N. and M.Y.; methodology, M.R.; software, M.R.; validation, M.R.; formal analysis, M.R.; investigation, all authors.; resources, M.R.; data curation, M.R.; writing—original draft preparation, all authors; writing — review and editing, all authors; visualization, all authors; supervision, M.R.; project administration, M.R., J.J., N.N. and M.Y. All authors have read and agreed to the published version of the manuscript.

\subsection{Funding}

The authors received no financial support for the research, authorship, and/or publication of this article.

\subsection{Acknowledgements}

The authors would like to appreciate the experts for their valuable comments and suggestion. The authors would also like to mention the university students to assist during data collection.

\subsection{Ethical Approval}

All subjects gave their informed consent for inclusion before they participated in the study. The study was conducted in accordance with the Declaration of Helsinki, and the protocol was approved the Bangladesh University of Professionals (BUP) Institutional Review Board (Research Ethics Committee).

\subsection{Data Availability Statement}

The data presented in this study are available in article.

\subsection{Conflict of Interest}

The authors declare that they have no known competing financial interests or personal relationships that could have appeared to influence the work reported in this paper.

\section{References}

[1] Deng, C.-X. (2020). The global battle against SARS-CoV-2 and COVID-19. International Journal of Biological Sciences, 16(10), 1676-1677. doi:10.7150/ijbs.45587.

[2] Hayat, K., Rosenthal, M., Xu, S., Arshed, M., Li, P., Zhai, P., Desalegn, G. K., \& Fang, Y. (2020). View of Pakistani Residents toward Coronavirus Disease (COVID-19) during a Rapid Outbreak: A Rapid Online Survey. International Journal of Environmental Research and Public Health, 17(10), 3347. doi:10.3390/ijerph17103347.

[3] Hua, J., \& Shaw, R. (2020). Corona Virus (COVID-19) "Infodemic" and Emerging Issues through a Data Lens: The Case of China. International Journal of Environmental Research and Public Health, 17(7), 2309. doi:10.3390/ijerph17072309.

[4] Zhang, H., \& Shaw, R. (2020). Identifying Research Trends and Gaps in the Context of COVID-19. International Journal of Environmental Research and Public Health, 17(10), 3370. doi:10.3390/ijerph17103370.

[5] Zhong, B.-L., Luo, W., Li, H.-M., Zhang, Q.-Q., Liu, X.-G., Li, W.-T., \& Li, Y. (2020). Knowledge, attitudes, and practices towards COVID-19 among Chinese residents during the rapid rise period of the COVID-19 outbreak: A quick online crosssectional survey. International Journal of Biological Sciences, 16(10), 1745-1752. doi:10.7150/ijbs.45221.

[6] COVID-19 Map. (2020). Johns Hopkins Coronavirus Resource Center. Available online: https://coronavirus.jhu.edu/map.html (accessed on 13 November 2020).

[7] Namazi, H., \& Kulish, V. V. (2020). Complexity-Based Classification of the Coronavirus Disease (COVID-19). Fractals, 28(5), 2050114-S68. doi:10.1142/S0218348X20501145.

[8] Ozili, P. K., \& Arun, T. (2020). Spillover of COVID-19: Impact on the Global Economy (SSRN Scholarly Paper ID 3562570). Social Science Research Network. doi:10.2139/ssrn.3562570.

[9] Zhou, F., Yu, T., Du, R., Fan, G., Liu, Y., Liu, Z., Xiang, J., Wang, Y., Song, B., Gu, X., Guan, L., Wei, Y., Li, H., Wu, X., Xu, J., Tu, S., Zhang, Y., Chen, H., \& Cao, B. (2020). Clinical course and risk factors for mortality of adult inpatients with COVID19 in Wuhan, China: A retrospective cohort study. The Lancet, 395(10229), 1054-1062. doi:10.1016/S0140-6736(20)30566-3. 
[10] Rahman, M. M., Khan, S. J., Sakib, M. S., Chakma, S., Procheta, N. F., Mamun, Z. A., Arony, A., Rahman, F., \& Rahman, M. M. (2020). Assessing the psychological condition among general people of Bangladesh during COVID-19 pandemic. Journal of Human Behavior in the Social Environment, 1-15. doi:10.1080/10911359.2020.1848688.

[11] Shammi, M., Bodrud-Doza, M., Towfiqul Islam, A. R. M., \& Rahman, M. M. (2020). COVID-19 pandemic, socioeconomic crisis and human stress in resource-limited settings: A case from Bangladesh. Heliyon, 6(5), e04063. doi:10.1016/j.heliyon.2020.e04063

[12] Arshad Ali, S., Baloch, M., Ahmed, N., Arshad Ali, A., \& Iqbal, A. (2020). The outbreak of Coronavirus Disease 2019 (COVID-19)-An emerging global health threat. Journal of Infection and Public Health, 13(4), $644-646$. doi:10.1016/j.jiph.2020.02.033

[13] Lai, C.-C., Wang, C.-Y., Wang, Y.-H., Hsueh, S.-C., Ko, W.-C., \& Hsueh, P.-R. (2020). Global epidemiology of coronavirus disease 2019 (COVID-19): Disease incidence, daily cumulative index, mortality, and their association with country healthcare resources and economic status. International Journal of Antimicrobial Agents, 55(4), 105946. doi:10.1016/j.ijantimicag.2020.105946.

[14] Ali, A. (1999). Climate change impacts and adaptation assessment in Bangladesh. Climate Research, 12, $109-116$. doi:10.3354/cr012109.

[15] Chanda Shimi, A., Ara Parvin, G., Biswas, C., \& Shaw, R. (2010). Impact and adaptation to flood: A focus on water supply, sanitation and health problems of rural community in Bangladesh. Disaster Prevention and Management: An International Journal, 19(3), 298-313. doi:10.1108/09653561011052484.

[16] Mutsuddy, P., Tahmina Jhora, S., Shamsuzzaman, A. K. M., Kaisar, S. M. G., \& Khan, M. N. A. (2019). Dengue Situation in Bangladesh: An Epidemiological Shift in terms of Morbidity and Mortality [Research Article]. Canadian Journal of Infectious Diseases and Medical Microbiology; Hindawi. doi:10.1155/2019/3516284

[17] Steckler, M. S., Mondal, D. R., Akhter, S. H., Seeber, L., Feng, L., Gale, J., ... Howe, M. (2016). Locked and loading megathrust linked to active subduction beneath the Indo-Burman Ranges. Nature Geoscience, 9(8), 615-618. doi:10.1038/ngeo2760.

[18] Glass, R. I., Becker, S., Huq, M. I., Stoll, B. J., Khan, M. U., Merson, M. H., Lee, J. V., \& Black, R. E. (1982). Endemic Cholera in Rural Bangladesh, 1966-1980. American Journal of Epidemiology, 116(6), 959-970. doi:10.1093/oxfordjournals.aje.a113498.

[19] Rahman, M., \& Chakraborty, A. (2012). Nipah virus outbreaks in Bangladesh: A deadly infectious disease. WHO South-East Asia Journal of Public Health, 1(2), 208. doi:10.4103/2224-3151.206933.

[20] Mamun, M. A., \& Griffiths, M. D. (2020). First COVID-19 suicide case in Bangladesh due to fear of COVID-19 and xenophobia: Possible suicide prevention strategies. Asian Journal of Psychiatry, 51, 102073. doi:10.1016/j.ajp.2020.102073.

[21] COVID-19 General Information. (2020). IEDCR. Available online: https://iedcr.gov.bd/covid-19/covid-19-generalinformation (accessed on 12 November 2020).

[22] Anwar, S., Nasrullah, M., \& Hosen, M. J. (2020). COVID-19 and Bangladesh: Challenges and How to Address Them. Frontiers in Public Health, 8. doi:10.3389/fpubh.2020.00154.

[23] Shammi, M., Bodrud-Doza, Md., Islam, A. R. Md. T., \& Rahman, Md. M. (2020). Strategic assessment of COVID-19 pandemic in Bangladesh: Comparative lockdown scenario analysis, public perception, and management for sustainability. Environment, Development and Sustainability. doi:10.1007/s10668-020-00867-y.

[24] Gohel, K. H., Patel, P. B., Shah, P. M., Patel, J. R., Pandit, N., \& Raut, A. (2021). Knowledge and perceptions about COVID19 among the medical and allied health science students in India: An online cross-sectional survey. Clinical Epidemiology and Global Health, 9, 104-109. doi:10.1016/j.cegh.2020.07.008.

[25] Basir, N. A. B. A., Rahman, N. A. A., Haque, M., Basir, N. A. B. A., Rahman, N. A. A., \& Haque, M. (2020). Knowledge, Attitude and Practice Regarding Pertussis among a Public University Students in Malaysia. Pesquisa Brasileira Em Odontopediatria e Clínica Integrada, 20. doi:10.1590/pboci.2020.002.

[26] Chen, Y., Fang, L., \& Liu, X. W. (2015). Survey of status quo of disaster response knowledge and skills of non-medical college students in Xi'an City. Chinese Nursing Research, 11, 1315-1318.

[27] Gillani, A. H., Mohamed Ibrahim, M. I., Akbar, J., \& Fang, Y. (2020). Evaluation of Disaster Medicine Preparedness among Healthcare Profession Students: A Cross-Sectional Study in Pakistan. International Journal of Environmental Research and Public Health, 17(6), 2027. doi:10.3390/ijerph17062027.

[28] Rahman, M. M., Khan, S. J., Sakib, M. S., Halim, M. A., Rahman, M. M., Asikunnaby, \& Jhinuk, J. M. (2021). COVID-19 responses among university students of Bangladesh: Assessment of status and individual view toward COVID-19. Journal of Human Behavior in the Social Environment, 1-20. doi:10.1080/10911359.2020.1822978. 
[29] Rahman, M. M., Khan, S. J., Sakib, M. S., Halim, M. A., Rahman, F., Rahman, M. M., Jhinuk, J. M., Nabila, N. H., \& Yeasmin, M. T. M. (2021). COVID-19 responses among general people of Bangladesh: Status and individual view toward COVID-19 during lockdown period. Cogent Psychology, 8(1), 1860186. doi:10.1080/23311908.2020.1860186.

[30] Cao, W., Fang, Z., Hou, G., Han, M., Xu, X., Dong, J., \& Zheng, J. (2020). The psychological impact of the COVID-19 epidemic on college students in China. Psychiatry Research, 287, 112934. doi:10.1016/j.psychres.2020.112934.

[31] Mamun, M. A., Chandrima, R. M., \& Griffiths, M. D. (2020). Mother and Son Suicide Pact Due to COVID-19-Related Online Learning Issues in Bangladesh: An Unusual Case Report. International Journal of Mental Health and Addiction. doi:10.1007/s11469-020-00362-5.

[32] Ursachi, G., Horodnic, I. A., \& Zait, A. (2015). How Reliable are Measurement Scales? External Factors with Indirect Influence on Reliability Estimators. Procedia Economics and Finance, 20, 679-686. doi:10.1016/S2212-5671(15)00123-9.

[33] RStudio | Open source \& professional software for data science teams. Available online: https://rstudio.com/ (accessed on 15 January 2021).

[34] Covid-19: 73\% of the deceased in Bangladesh are male. (2020, May 19). The Business Standard. Available online: https://tbsnews.net/coronavirus-chronicle/covid-19-bangladesh/covid-19-73-deceased-bangladesh-are-male-83260 (accessed on 19 May 2020).

[35] Walter, L. A., \& McGregor, A. J. (2020). Sex- and Gender-specific Observations and Implications for COVID-19. Western Journal of Emergency Medicine: Integrating Emergency Care with Population Health, 21(3). doi:10.5811/westjem.2020.4.47536.

[36] Akram, A. (2019). Alarming Turn of Dengue Fever in Dhaka City in 2019. Bangladesh Journal of Infectious Diseases, 6(1), 12. doi:10.3329/bjid.v6i1.42627.

[37] Chowdhury, P. (2017). Combating Urban Hazard: A Qualitative Study of Disaster Preparedness in Dhaka, Bangladesh. Available online: http://lup.lub.lu.se/student-papers/record/8918581 (accessed on 17 March 2021).

[38] H., \& Islam, S. (2015). Awareness and Preparedness of Disasters in Bangladesh-A Study of Dhaka City Dwellers. Social Science Review, The Dhaka University Studies.

[39] Rahman, N., Ansary, M. A., \& Islam, I. (2015). GIS based mapping of vulnerability to earthquake and fire hazard in Dhaka city, Bangladesh. International Journal of Disaster Risk Reduction, 13, 291-300. doi:10.1016/j.ijdrr.2015.07.003.

[40] Islam, R., Islam, M. N., \& Islam, M. N. (2016). Earthquake risks in Bangladesh: Causes, vulnerability, preparedness and strategies for mitigation. ARPN Journal of Earth Sciences (JES), 5(2), 75-90.

[41] Paul, B. K., \& Bhuiyan, R. H. (2010). Urban earthquake hazard: Perceived seismic risk and preparedness in Dhaka City, Bangladesh. Disasters, 34(2), 337-359. doi:10.1111/j.1467-7717.2009.01132.x.

[42] Saiful Islam, A. B. M., Jameel, M., Rahman, M. A., \& Jumaat, M. Z. (2011). Earthquake time history for Dhaka, Bangladesh as competent seismic record. International Journal of Physical Sciences, 6(16), 3921-3926.

[43] Hoffmann, R., \& Muttarak, R. (2017). Learn from the Past, Prepare for the Future: Impacts of Education and Experience on Disaster Preparedness in the Philippines and Thailand. World Development, 96, 32-51. doi:10.1016/j.worlddev.2017.02.016.

[44] Tan, Yibing, Xiaolan Liao, Haihao Su, Chun Li, Jiagen Xiang, and Zhaoyang Dong. "Disaster Preparedness among University Students in Guangzhou, China: Assessment of Status and Demand for Disaster Education.” Disaster Medicine and Public Health Preparedness 11, no. 3 (September 26, 2016): 310-317. doi:10.1017/dmp.2016.124.

[45] Bao, H., Cao, B., Xiong, Y., \& Tang, W. (2020). Digital Media's Role in the COVID-19 Pandemic. JMIR MHealth and UHealth, 8(9), e20156. doi:10.2196/20156.

[46] Goel, A., \& Gupta, L. (2020). Social Media in the Times of COVID-19. JCR: Journal of Clinical Rheumatology, 26(6), 220223. doi:10.1097/rhu.0000000000001508.

[47] Karasneh, R., Al-Azzam, S., Muflih, S., Soudah, O., Hawamdeh, S., \& Khader, Y. (2021). Media's effect on shaping knowledge, awareness risk perceptions and communication practices of pandemic COVID-19 among pharmacists. Research in Social and Administrative Pharmacy, 17(1), 1897-1902. doi:10.1016/j.sapharm.2020.04.027. 